$\begin{array}{r}\text { Volume and Issues Obtainable at Center for Sustainability Research and Consultancy } \\ \text { Journal of Business and Social Review in Emerging Economies } \\ \text { ISSN: 2519-089X (E): 2519-0326 } \\ \text { Volume 6: No. 4, December 2020 } \\ \text { CSRᄃ } \\ \text { Journal homepage: www.publishing.globalcsrc.org/jbsee } \\ \hline\end{array}$

\title{
Interrelation of Multiple Intelligences and their Correlation with Linguistic Intelligence as Perceived by College Students: A Correlation Study
}

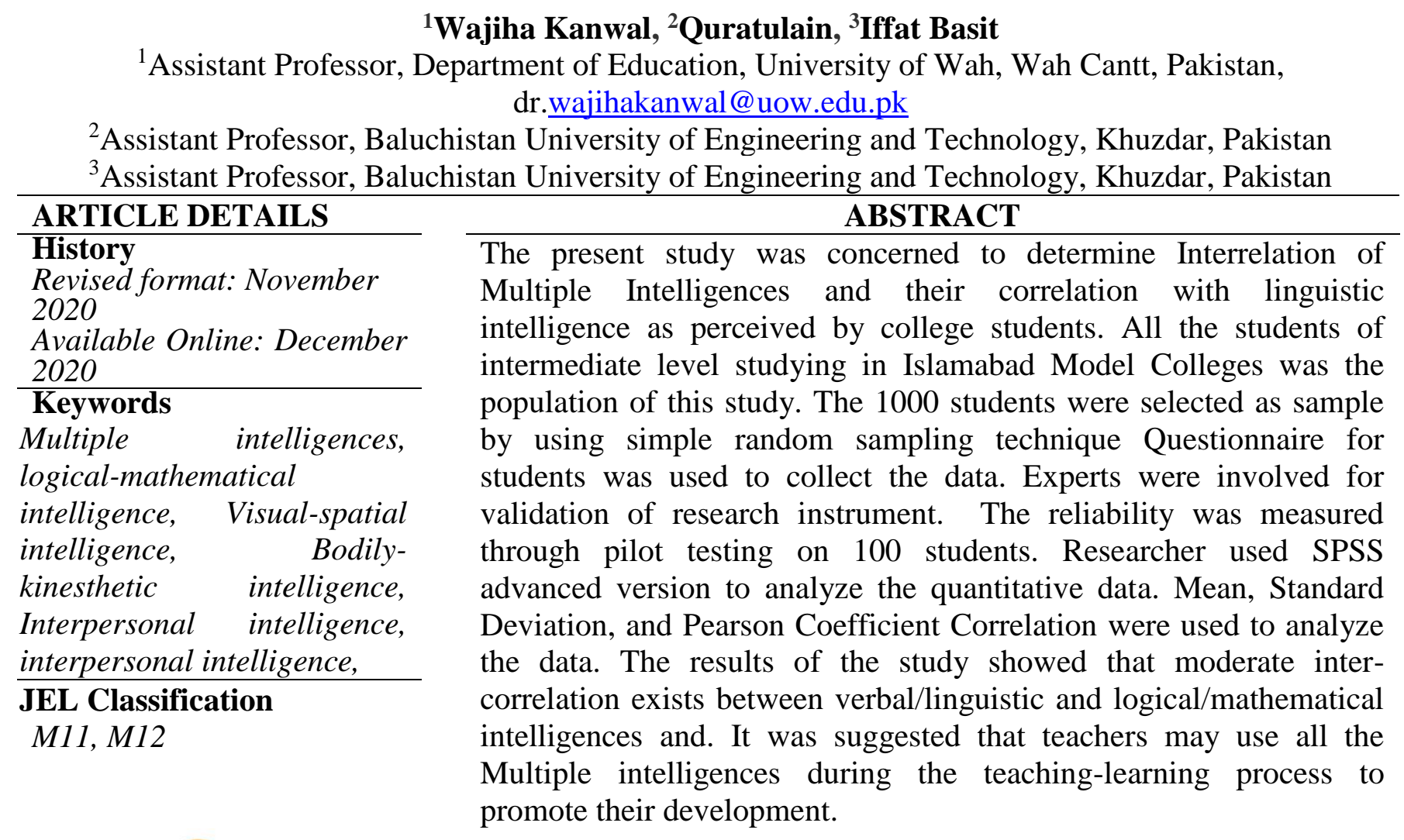
a Creative Commons Attribution-NonCommercial-ShareAlike 4.0

Corresponding author's email address: dr. wajihakanwal@uow.edu.pk

Recommended citation: Kanwal, W., Quratulain. \& Basit, I. (2020). Interrelation of Multiple Intelligences and their Correlation with Linguistic Intelligence as Perceived by College Students: A Correlation Study. Journal of Business and Social Review in Emerging Economies, 6(4), 1439-1447

\section{Introduction}

With the technique of mental cerebrum technology as the ones accepted norms to training, teachers carry discover a top tempo charmed via way of means of serving understudies make considering techniques. How college students envision want rework into Pretty a lot this is only a glimpse of something large large over what they consider. MI concept offers an Ideal affiliation with selecting getting a manage on approximately understudies' highbrow aptitudes. The 8 insights with inside the version want assist themselves highbrow limits. Thus, to make any or at for them with inside the guides delineated to beyond components might be on empowering the ones enhancements of understudies' capacity to think. MI may also an possibility to be useful, in any case, on gander this is only a glimpse of somthing large, particularly In how mi tenet applies of the zone's (Bowell, 2004; Chen, 2007) This studies changed into designed as Relationship of Linguistic intelligence with Multiple Intelligences: A Correlation observe 
at Collage college students Actually studies to test the connection among a couple of intelligences with linguistic intelligence. The main objectives of the study were to determining students perceived levels of multiple intelligences and Identifying the correlation between Linguistic Intelligence with other multiple intelligences

\section{Hypotheses}

1. $\mathrm{H}_{0} 1$ "There is no significant relationship between Linguistic Intelligence and Logical Mathematical Intelligence of students at higher secondary level".

2. $\mathrm{H}_{0} 2$ "There is no significant relationship between Linguistic Intelligence and Bodily/kinesthetic Intelligence of students at higher secondary level".

3. $\mathrm{H}_{0} 3$ "There is no significant relationship between Linguistic Intelligence and visual/Spatial Intelligence of students at higher secondary level".

4. $\mathrm{H}_{0} 4$ "There is no significant relationship between Linguistic Intelligence and Musical Intelligence of students at higher secondary level".

5. $\mathrm{H}_{0} 5$ "There is no significant relationship between Linguistic Intelligence and Intrapersonal Intelligence of students at higher secondary level".

6. $\mathrm{H}_{0} 6$ "There is no significant relationship between Linguistic Intelligence and Interpersonal Intelligence of students at higher secondary level”.

\section{Review of Related Literature}

The phonetic Knowledge embarrasses verbal articulation via numerous dialects, so that it will speak round your thoughts similarly because it desires to apprehend others. (Checkley, 1997) The etymological perception lets in humans to speak with the universe via language via vernacular. Specialists epitomize this velocity over it is made structure. Students who exhibits hobby in rhymes, making jokes etc. surely tents to talk their inward notion via way of means of the use of languages. It consists of verbal exchange through gestures to illustrate linguistic highbrow competence. (Gardner, 1919).

Reasonable logical know-how permits people to apply and understand dynamic relations. Researcher, mathematicians, furthermore scientists all rely in advance this insight. Individuals with an astoundingly generated shrewd numerical know-how draw close the essential standards whch leads them to nation each a part of a comprehensive causal framework, like a researcher or an analyst does. This kind of intelligence may also facilitate mathematicians to manipulate numbers, quantities and different comparable activities. (Checkley, 1999).

Musical intelligence refers back to the capacity to ruminate in track, functionality to listen melodious patterns, distinguish among numerous musical melodies, reminisce them, and likely manage them. People with resilient musical intelligence can't simplest keep in mind track without difficulty however they even can not get it out in their minds, it is very pervasive. Remarkably, there's commonly an affective affiliation among feelings and the track; likewise musical and mathematical intelligences might also additionally stake not unusualplace philosophy.

Young people having this type of intelligence are commonly interested by making a song an gambling musical gadgets like beating drums etc. They are frequently particularly greater aware about sounds and descants that others might also additionally neglect. People with musical intelligence relatively greater respect track and musical composition and performance. Melodic awareness is the potential to suppose in track, have to have the capacity to concentrate designs, apprehend them, evaluation them, and possibly manage them. ".

Campanulated (1997) recommends that teachers who want to enhance melodic highbrow competence camwood sing a rap or a song that explains the ones topics (Checkley, 1997). Portrays melodic quickness the "track keen" people experience approximately track, tuning in for examples, perceiving, recalling, and controlling them. They are first-class thru resonances for remembering tuning for 
moreover making resonances for instance, to such an volume that melodies, rhythms, designs, what greater numerous varieties of sound associated outpouring. They have the capacity to apply inductive moreover deductive reasoning are greater understand institutions up data (Lazaer, 2002).

Spatial intelligence joins the restrict need to understand the visible fact impeccably and to carry out modifications likewise changes upon one's very own beginning acknowledgments via intellectual imagery. Down to earth views from ensuring spatial cleverness consolidate tasteful structure, map perusing, moreover an terrific clothier would require each the modern capacities and also specific foul accomplishing. An car laborer or clothier, then again, does not convincing clarification modern What's steadily tasteful capacities need to discover the final results need to a stalling engine (Gardner, 1999). Spatial awareness pastime the "photo keen" relatives want the restrict will cope with the spatial globe over their minds. In this way, they growth satisfactory seemingly what is steadily have a tendency need to sift via their thinking about spatially (Lazaer, 2000).

Portrays that significant sensation perception licenses people to apply all alternatively and simply the ones particular figures to make outcomes or take care of problems. Competitors, specialists, artists, choreographers, and specialties people constantly on the use of physical sensation perception activity. The ability is also disposed towards must do population endeavors Inevitably Tom's investigative manufacture fashions as confined forming reports, who toss deteriorated piece of a paper with repeat in addition to precision under waste baskets in extra of these space (Gardner, 1999.

Gardner (1999) Relational understanding engages people should apprehend exasperate differentiations, some thing like others aims. Instructors, guardians, legislators, clinicians and gives people rely investigating relational acumen pastime. Researchers display this acumen pastime once they prosper as for little collecting effort, at what time they come to be aware about react of the temperaments because putting forward their companion's in addition to schoolmates, through their thoughtfully persuade people teacher's affirmation concerning their convincing motivation in the direction of more second be meant to finish the ones schoolwork obligations. Relational astuteness comprehends diverse people. It's a capability we at want, regardless are a top rate at the off risk which you could an instructor, clinician, income rep, or lawmaker. Any character who can wish for others want have to an possibility to successful of relational encircle (Checkley, 1997.

Intrapersonal means what your identification is, the issue that you can do, what you need to do, the way you react ought to matters, which matters to hold away from, moreover which matters will skim towards (Gardner, 1999). gift one of the maximum clean preparations of phrases. Those taking in fashion composing suggests an awesome display for phrases that want assist comparable, but without a doubt unique. Explanation from affirming that is critical to a comprehension for problems in steerage arrangement. Those an considerable phase putting length that separates the ones phrases slanting fashion, taking in approach, taking in tendency highbrow fashion is that degree on which they will be considered clarified. Styles: Classifications, thoughts (Curry,1991, Riding and Cheema, 1991).

MI principle facilities around a first rate type of understudies' perception underlined via way of means of Davis, (1991) expressed that it elevates diverse techniques to learn. Due to rigid instructional plan, great numbers college students lose redirections to in a direct outcome. Every child has inherent abilities, be that during our informational establishment's instructive module first-class fixated on verbal/phonetic and consistent/medical cleverness. Instructors ought to have the ability of examine the ones inward global approximately every person, in order make on the other hand increase every youngster's distinctiveness with accommodating them a perfect approach for education. Additionally see distinctiveness likewise reliably convincing motivation to make cautious for every thrilling difference.

Different intellectual capacity hypothesis is robust to instructors to get it contrasts from ensuring each character makes every one's capacity and plausibility and get-togethers supply becoming mindfulness 
regarding the individuals who are being all through peril starting with educational dissatisfaction. Instructors' idea might also additionally make him is land at perceiving some thing like differentiation to understudies' learning, and the one-of-a-kind knowledge (Zepke, 1997).

\section{Methodology}

\subsection{Participants}

Sample of the study was extracted by using simple random sampling technique hence twenty Federal Highr Secondary Colleges were selected. Amongst 48000 students enrolled in these colleges total 1000 students (50 students per college) were chosen in order to collect data for the study.

\subsection{Instrumentation}

Howard Gardner's multiple intelligences test was selected as data collection instrument. It was adapted according to study requirement therefore it was presented to three experts to ascertain its validaty. Research tool was then pilot tested and after that it was administered to the selected sample Questionnaire of this study was consist of 44 statements. Gardner's seven multiple intelligences 5 on LI , 10 on L/MI, 6 on V/SI, 6 on B/KI, 3 on MI, 4 on IPI ( intra personal intelligence), 10 on II ( interpersonal intelligence). Pearson ' $r$ ' Correlation was employed to analyse data.

\section{Findings}

Table 1

Inter-Correlation among Various Multiple intelligence $\quad(\mathrm{N}=1000)$

\begin{tabular}{llllllll}
\hline Cognitive Styles & 1 & 2 & 3 & 4 & 5 & 6 & 7 \\
\hline Linguistic Intelligence & 1 & & & & & & \\
Logical/ Mathematical Intelligence & $0.26^{*}$ & 1 & & & & & \\
Bodily/kinesthetic Intelligence & $0.16^{*}$ & $0.25^{*}$ & 1 & & & & \\
Vision/Spatial Intelligence & $0.23^{*}$ & $0.17^{*}$ & $0.41^{*}$ & 1 & & & \\
Musical Intelligence & $0.15^{*}$ & 0.03 & $0.26^{*}$ & $0.20^{*}$ & 1 & & \\
Intrapersonal Intelligence & $0.16^{*}$ & $0.18^{*}$ & $0.18^{*}$ & $0.17^{*}$ & $0.25^{*}$ & 1 & \\
Interpersonal Intelligence & $0.26^{*}$ & $0.16^{*}$ & $0.38^{*}$ & $0.30^{*}$ & $0.23^{*}$ & $0.30^{*}$ & 1 \\
\hline \multicolumn{2}{c}{$*$ Correlation is significant at the 0.01 level } & & & &
\end{tabular}

Table 1 describes the inter-correlation among various multiple intelligences as perceived by students. The highest correlation exists between Bodily/kinesthetic Intelligence and Vision/Spatial Intelligence ( $\mathrm{r}$ $=0.38, \mathrm{p} \leq .01)$. The lowest correlation exist between Logical Mathematical Intelligence and Musical Intelligence $(\mathrm{r}=0.03, \mathrm{p} \leq .01)$.

Ho1: "There is no significant relationship between Linguistic Intelligence and Logical Mathematical Intelligence of students at higher secondary level".

Table 2.

Correlation between Linguistic Intelligence and Logical Mathematical Intelligence mean score.

\begin{tabular}{llllll}
\hline Variables & $\mathrm{N}$ & Mean & SD & Pearson 'r' & Sig (2-tailed) \\
\hline Linguistic & 1000 & 16.81 & 3.678 & 0.261 & 0.000
\end{tabular}


"Correlation is significant at the 0.01 level (2-tailed)"

Table 2 describes the value of correlation coefficient "(Pearson ' $r$ ' $=0.261)$ " between Linguistic and Logical Mathematical Intelligence as perceived by college students. Result indicates positive correlation between Linguistic and Logical intelligence.

Ho2: "There is no significant relationship between Linguistic Intelligence and Bodily/kinesthetic Intelligence of students at higher secondary level".

Table 3

Correlation between Linguistic Intelligence and Bodily/kinesthetic Intelligence mean score.

\begin{tabular}{lccccc}
\hline Variables & N & Mean & SD & Pearson 'r' & Sig (2-tailed) \\
\hline Linguistic & 1000 & 16.81 & 3.678 & 0.157 & 0.000 \\
Bodily/kinesthetic & 1000 & 21.88 & 4.391 & \\
\hline & \multicolumn{5}{c}{ "Correlation is significant at the 0.01 level (2-tailed)" }
\end{tabular}

Table 3 indicates the scale of correlation coefficient "(Pearson ' $r$ ' $=0.157)$ " between Linguistic and Bodily/kinesthetic Intelligence. From the table it appear that positive correlation involving Linguistic Intelligence and Bodily/kinesthetic Intelligence here is no significant relationship

Ho3: "There is no significant relationship between Linguistic Intelligence and visual/Spatial Intelligence of students at higher secondary level".

Table 4.

Correlation between Linguistic Intelligence and visual/Spatial Intelligence mean score.

\begin{tabular}{llllll}
\hline Variables & $\mathrm{N}$ & Mean & SD & Pearson 'r' & Sig (2-tailed) \\
\hline Linguistic & 1000 & 16.81 & 3.678 & 0.231 & 0.000 \\
visual/Spatial & 1000 & 21.79 & 4.446 & & \\
\hline
\end{tabular}

"Correlation is significant at the 0.01 level (2-tailed)"

table 4. reflects the level of correlation coefficient "(Pearson ' $r$ ' $=0.231)$ " whe indicates strong positive relationship between Linguistic and visual/Spatial Intelligence.

H04: "There is no significant relationship between Linguistic Intelligence and Musical Intelligence of students at higher secondary level".

Table 6. "Correlation between Linguistic Intelligence and Musical Intelligence mean score".

\begin{tabular}{llllll}
\hline Variables & $\mathrm{N}$ & Mean & SD & Pearson 'r' & Sig (2-tailed) \\
\hline Linguistic & 1000 & 16.81 & 3.678 & 0.148 & 0.000 \\
Musical & 1000 & 10.33 & 3.556 & & \\
\hline
\end{tabular}

"Correlation is significant at the 0.01 level (2-tailed)" 
Table 6 displays degree of the correlation coefficient "(Pearson ' $r$ '=0. 148)" between Linguistic and Musical Intelligence. It reveals positive correlation and insignificant relationship between LI and MI.

H05: "There is no significant relationship between Linguistic Intelligence and Intrapersonal Intelligence of students at higher secondary level".

Table 7

Correlation between Linguistic Intelligence and Intrapersonal Intelligence mean score

\begin{tabular}{llllll}
\hline Variables & $\mathrm{N}$ & Mean & SD & Pearson 'r' & Sig (2-tailed) \\
\hline Linguistic & 1000 & 16.81 & 3.678 & 0.156 & 0.000 \\
Intrapersonal & 1000 & 14.98 & 3.240 & & \\
\hline
\end{tabular}

"Correlation is significant at the 0.01 level (2-tailed)"

Table 7 clarify that the degree of correlation coefficient "(Pearson ' $r$ ' $=0.156)$ "shows strong positive correlation with Linguistic and Intrapersonal Intelligence as perceived by collage students. They have no significant relationship between LI and Intrapersonal Intelligence.

Ho6: There is no significant relationship between Linguistic Intelligence and Interpersonal Intelligence of students at higher secondary level.

Table 8

Correlation between Linguistic Intelligence and Interpersonal Intelligence mean score

\begin{tabular}{lccccc}
\hline Variables & $\mathrm{N}$ & Mean & SD & Pearson 'r' & Sig (2-tailed) \\
\hline Linguistic & 1000 & 16.81 & 3.678 & 0.264 & 0.000 \\
Interpersonal & 1000 & 41.90 & 5.992 & &
\end{tabular}

"Correlation is significant at the 0.01 level (2-tailed)"

Table 6 specify that level of correlation coefficient "(Pearson ' $r$ ' $=0.264)$ " disccloses positive correlation between Linguistic and Interpersonal Intelligence.

\section{Discussion}

College students have special stage of intelligence which distinguish them from every different. A comparative and essential stance on outcomes and findings of the observe said that LI and L LI and $\mathrm{B} / \mathrm{KI}$ have superb correlation however no great courting exist among each classes of intelligence. Research with the aid of using Deary, et al., (2007), helps the result of prenent observe It is likewise inconsonance with the outcomes of who observed sturdy and superb courting among logical/mathematical intelligence and educational success. Furnham, Hosoe, \& Tang (2002), observed of their studies, that the respondents taken into consideration that verbal, logical and spatial intelligence exemplify proper intelligence. Therefore the null speculation rejected. Both don't have any great relation at the bases of statistical analysis. Here the outcomes of the observe showed the declare of Gardner. He says that despite the fact that a couple of intelligences are separate gadgets however they assist every different on every occasion a process is performed. The researcher additionally observed a slight affiliation among verbal/linguistic, logical/mathematical intelligence and educational success. 
Result of the observe is in consonance with, Siti, M. et al (2013), he observed in his observe a great superb correlation among verbal/linguistic, logic/mathematical intelligences and educational success of the college students. It is proved from the findings of this studies that there may be a great courting among Linguistic Intelligence and Bodily/kinesthetic Intelligence. Therefore the null speculation that right here isn't any significant courting among Linguistic Intelligence and Bodily/kinesthetic Intelligence of college students at better secondary stage became customary at the bases of statistical analysis.

Our findings are supported with the aid of using the preceding researches that have been performed on same variables which gift observe focused upon. The outcomes of Deary, et al., (2007), who observed a great superb correlation among perceived verbal-linguistic intelligence and bodily/kinesthetic intelligence. As said above the findings of the studies that there may be great courting among Linguistic Intelligence and visual/Spatial Intelligence. Hence, the null speculation that right here isn't any significant courting among Linguistic Intelligence and visual/Spatial Intelligence of college students at better secondary stage became rejected at the bases of statistical analysis. Furthermore, there may be great courting among Linguistic Intelligence and Musical Intelligence. Thus the null speculation that tright here isn't anyt any significant courting among Linguistic Intelligence and Musical Intelligence of college students at better secondary stage became rejected at the bases of statistical analysis.

Moreover, the findings of this studies suggests that there may be great courting among Linguistic Intelligence and Intrapersonal Intelligence. So the null speculation that tright here isn't anyt any significant courting among Linguistic Intelligence and Intrapersonal Intelligence of college students at better secondary stage became rejected on the idea of statistical analysis. The findings of this studies additionally proved that there may be great courting among Linguistic Intelligence and Interpersonal Intelligence. therefore the null speculation that tright here isn't anyt any significant courting among Linguistic Intelligence and Interpersonal Intelligence amongst college students at better secondary stage became customary on the idea of statistical analysis.

\section{Conclusions and Recommendations}

Overall the study was conducted to examine self perception of college students of both science and arts group studying at higher secondary level, about seven multiple intelligences proposed by Harward Gardner. The degree of correlation coefficient among Linguistic Intelligence, Logical Mathematical Intelligence, Bodily/kinesthetic Intelligence, Spatial Intelligence, Musical Intelligence, Intra Personal Intelligence and Inter Personal Intelligence mean score was significant. It was concluded that positive correlation exist among all multiple intelligences as perceived by higher secondary school students.

As present study explored that all caregories of intelligence may have positive impact on academic achievement of students so it is recommended that teacher may consider these intelligences while planning their lessons. Further more, experimental studies may possibly be carried out study in perspective of diverse demographic variable like age groups, geographical area, eacademic programs etc. in order to explore actual interelation among all multiple intelligences with each other and their correlation with linguistic intelligences.

\section{*Respected Editor}

The following article is taken from chapter-4 from thesis work of Dr.Qurat Ul AIN., which was submitted to the Higher Education Commission of Pakistan due to which the similarity index is above from the required, it is also mentioned that the following work was not published in any journal before. 


\section{References}

Anastasi,A.(1983c).what do intelligence tests measure? In S.B. Anderson\& J.S. Helmick

(Eds.), On educational testing . San Francisco: Jossey-Bass.

Beishuizen, J. J., \& StoutJ'csdiJ'k E T (1999) Study strategies In a computer assisted study environment. Learning and Instruction, 9(3), 281-30 I.

Blythe. T., \& Gardner, H. (J 990). A school for all intelligences. Educational Leadership,

Bouton, D.A. (1997). Operationalizing Multiple intelligences theory with adolescent Bulletin, 80 Psychology, 68,427-441.

Bloomington, IN: Phi Delta Kappan Educational Foundation, (ED 356 277) (highly recommended )

Cambpell ,L \& Cambpell (2000)' Multiple Intelligences and student achievement: Success Stories.

Campbell ,L \& Campbell (1999) Multiple Intelligences and Student Achievement: success stories from six schools, Alexandria, VA: Association for supervision and curriculum Development.

Campbell, B., Campbell, L and Dickinson(1996) Teaching and learning through Multiple Intelligences Needham Heights, MA: Allyn \& Bacon. curriculum Development.

Cano-Garcia, F., \& Hughes, E. H. (2000). Learning and Thinking Styles: An Analysis of Their Interrelationship and Influence on Academic Achievement. Educational Psychology: An International Journal of Experimental Educational Psychology, 20(4), 413-430.

Checkley, K. (1997) The first seven and the eight intelligence: A conversation with Howard Gardner. Educational Leadership: Teaching for multiple intelligence. ASCD V. 55, \#1, Setember 1997, 8-13.

Chen, J. (2004) Theory of multiple intelligences: Is it a scientifictheory? Teachers College Record, 106(1), 17-23.

Clark, (2001) Learning styles vary for adult student. Lana Ivanitskaya Executive Director, Organizational Research.

Claxton, C. S., \& Murrell, P. H. (1988). Learning Styles. ERIC Digest (EDO-HE-88- 6). Tennessee: ERIC Clearinghouse on Higher Education, Washington, DC. Oftice of Educational Research and Improvement (ED), Washington, DC.

Curry, L, (1991), Patterns of learning style across selected medical specialties Educational Psychology, 11,247-278.

Curry, Lynn. (1983). An Organization of learning style theory and constructs. ERIC Document,

Carroll, J.B. (1993). Human cognitive abilities: A survey of factor-analytic studies. Cambridge: Cambridge University Press.

Davidson, G, V., \& Savenye, W.S. (1992). How do learning styles relate to performance in a computer applications course? Journal of Research on computing in Education, 24(1), 348-358.

Davidson, J.E. (1990). Intelligence recreated. Educational Psychologist, 25(3-4), 337-354.

Davis, Russel. (1991). Learning How to learn: Technology, the Seven Multiple Intelligences and Learning. California: (ERIC Document Reproduction Service No. ED 338214). Educational Research Journal, 13, (1) 3-22

Dunn, R., \& Griggs, S. (1998) Learning Styles: Link between teaching and learning.In Dunn, R. \& Griggs, S.(Eds.), Learning styles and the nursing profession (pp. 11-23). New York: NLN press. I

Day, J. D., Engelhardt,J. L., Maxwell, S. E. \& Bolig, E. E. (1997). Comparison of static and dynamic assessment procedures and their relation to independent performance. Journal of Educational Psychology.

EIlison, L. (1992). Using multiple intelligences to set goals. Educational Arlington Public schools Web Page. http://Www.surfaquarium.com/im.htm

Feuerstein, R., Feuerstein, R., \& Gross, S. (1997). The learning potential Assessment Device. In 
D. P. Flanagan, J. Genshaft, \& P. L. Harrison (Eds.), Contemporary Intellectual assessment: Theories, tests, and issues. New York: Guilford.

Gigerenzer, G. (2004). Dread risk, September 11, and fatal traffic accidents. Psychological science, 15.

Gardner, H. (1983). Frames of mind: The theory of multiple intelligences. New York: Basic Books.

Gigerenzer; G., Todd, P. M., \& The ABC Research group (1999). Simple heuristics that make us smart. New York: Oxford University Press.

Gardner, H. (1999). Intelligence Reframed: Multiple Intelligence for the $21^{\text {st }}$ century. New York, NY: Basic Books.

Gardner, H. (2004). Audiences for the theory of multiple Intelligences. Teachers College Record, 106(1), 212-220

Guilford, J. L. (1954). The nature of human intelligence. New York: McGraw-Hill. Herrmann, N. (1982). The Creative brain. NASSP Bulletin, 31-45.

https://www.verywellmind.com/gardners-theory-of-multiple-intelligences-2795161

http://www.ascd.org/publications/educational-leadership/sept97/vol55/num01/The-First-Seven.-.-.-andthe-Eighth@-A-Conversation-with-Howard-Gardner.aspx 